\title{
COMUNICAÇÃO ESCOLAR E PEDAGOGIA DA COMUNICAÇÃO: o trabalho de Heloisa Dupas Penteado em perspectiva
}

\author{
Scholar communication and communication pedagogy: the work of \\ Heloisa Dupas Penteado in perspective
}

\begin{abstract}
Aldo Pontes
Docente da Universidade São Francisco (USF), Doutorando em Educação e Comunicação pela Faculdade de Educação da USP (FE-USP), Mestre em Tecnologia Educacional Faculdade Federal de Campinas (Unicamp). Campinas, SP - Brasil.

Contextualizar, pois, a educação escolarizada passa por: abrir o leque das linguagens oral e escrita; acolher os múltiplos textos por elas configurados, como os televisuais, musicais, dramáticos, fotográficos, cinematográficos, corporais; escutar as singularidades das expressões no conjunto das multifacetadas vozes. O que implica admitir a educação escolarizada como um processo de comunicação específico, cuja especificidade reside em um trabalho intencional com o conhecimento, e que supõe a substituição do processo didático massificante por uma metodologia comunicacional de ensino (PENTEADO, 1997, p. 89).
\end{abstract}

Ao nos propormos a apresentar um pouco do trabalho da profa. Dra. Heloisa Dupas Penteado, da Faculdade de Educação da USP, a certeza da tarefa quase que inabarcável é a primeira que se faz presente. Dizemos dessa forma por nos referirmos a uma professora pesquisadora que traz em seu currículo, ao lado de poucos outros, o pioneirismo nos estudos sobre a relação Educação e Comunicação no Brasil. Sendo sua principal contribuição a edificação das bases de uma Pedagogia da Comunicação.

Para essa pesquisadora, a escola é essencialmente um espaço de comunicação, o que faz com que toda ação educativa seja também uma ação comunicativa. Assim: “Ensino é comunicação [...]. Não qualquer tipo de comunicação. Mas comunicação dialógica. Não meramente reprodutora, mas elaboradora do conhecimento" (PENTEADO, 1991, p. 112).

A profa. Heloisa é socióloga e pós-doutora em Educação pela Pontifícia Universidade Católica do Rio de Janeiro (PUC-RJ), onde realizou estudos sobre a Comunicação escolar e a Pedagogia da Comunicação. Atualmente dedica-se à orientação de mestrandos e doutorandos no programa de pós-graduação em Educação, nas linhas de pesquisa Pedagogia da Comunicação e Formação de Professores. Além disso, coordena um projeto de pesquisa sobre telepsicodrama pedagógico, intitulado Telepsicodrama, pedagogia da comunicação e educação: formação em temas emergentes e urgentes. E também tem participado de congressos nacionais e internacionais relativos ao campo de convergência e diálogo da Educação e Comunicação. 
Dentre as publicações de sua autoria, destacam-se os livros Psicodrama, televisão e formação de professores; Comunicação Escolar: uma metodologia de ensino; Pedagogia da Comunicação: teorias e práticas; e Televisão e escola: conflito ou cooperação?.

Para conhecermos mais o trabalho dessa professora pesquisadora e compreendermos melhor suas teorias e práticas, a seguir damos voz à própria profa. Heloisa Dupas Penteado, por meio de uma entrevista gentilmente cedida para esta publicação.

1. Já faz alguns anos a senhora vem se dedicando ao estudo da relação Educação e Comunicação, chegando até mesmo a defender uma Pedagogia da Comunicação. Como e em que momento da sua carreira docente surgiu o interesse pelo estudo desse campo?

Meu interesse surgiu no início da década de 70, ocasião em que lecionava Estudos Sociais para $5^{\mathrm{a}}$ série, no GEPE (Ginásio Estadual Pluricurricular Experimental da Lapa), ocasião em que os alunos comentavam comigo sobre o que viam na TV e em que, com entusiasmo, se referiam a assuntos tratados por nós em aula, quando os encontravam comentados na TV. Percebia que a TV é que legitimava para eles tais assuntos, quando, no meu entender, essa legitimação deveria ser conferida pela instituição escola.

\section{Como a senhora vê o campo da Educação e Comunicação na atualidade?}

Como um campo em expansão, mas ainda não no ritmo em que considero necessário em nosso país. Pois no cenário internacional há hoje uma sensibilização para a importância de se trabalhar com a leitura de outros textos midiáticos na escola, além do texto impresso, especialmente o texto televisual, pelo seu alcance praticamente universal, o que se manifesta em encontros internacionais sobre o tema. Outro aspecto que me chama a atenção é o fato de que, com enorme frequência, o enfoque dado ao tema se restringe à presença das mídias eletrônicas na escola, o que por si só não garante um uso formativo e realmente educativo. Pois o que dá sentido ao trabalho com mídias na escola é a filosofia e os valores que sustentam essa inclusão, de onde decorre a metodologia com que devem ser trabalhadas.

\section{Que perspectivas vislumbra para o futuro desse campo?}

Vejo como um campo que não mais pode ser negado hoje, e daqui para diante, dada a sua presença irreversível na sociedade tecnológica da atualidade. Todavia, a qualidade do trabalho formativo a ser feito, se a serviço do homem e de sua humanização, depende basicamente de dois fatores aludidos anteriormente: a filosofia que sustenta essas práticas escolares e a correspondente Pedagogia da Comunicação, articuladora de uma metodologia de ensino responsável por uma verdadeira Comunicação Escolar.

4. Muitos nomes têm surgidopara denominar esse campo:Educação e Comunicação, Comunicação e Educação, Pedagogia da Comunicação, Comunicação Educativa, Educomunicação, Educação para Mídia... Qual desses nomes a senhora acha mais adequado? Por quê?

O nome que considero mais apropriado é Educação com Mídias. Não considero Pedagogia da Comunicação um nome para o campo, posto que tal denominação refere-se a procedimentos teóricometodológicos que dizem respeito ao trabalho educativo com o "objeto" de ensino - o fenômeno 
da comunicação. Quanto às denominações Comunicação Educativa, Educomunicação, entendo-os como pleonásticos, posto que "educação é comunicação". A educação é um processo social, seja ele institucionalizado ou não (socialização), e que, portanto, só se realiza nas relações sociais, portanto interpessoais (presenciais ou a distância). Na verdade entendo que o enfoque da comunicação no campo da educação deve contemplar dois aspectos fundamentais: a inclusão na escola das mídias presentes na sociedade tecnológica e a revisão dos procedimentos educacionais com mídias na perspectiva de processos comunicacionais humanizantes e democratizantes do saber e da capacidade criadora do ser humano.

\section{Com seus estudos e pesquisas, que contribuição específica a senhora julga estar dando, ou ter dado, para esse campo de estudos e pesquisas que é a Educação e Comunicação?}

Fico feliz se meu trabalho puder despertar professores para a importância de um trabalho comunicacional escolar com mídias na escola e entre os sujeitos dessa educação escolar (professores e alunos) enquanto sujeitos midiáticos. Ou seja, por sujeitos que processam as mensagens midiáticas de maneira pessoal e peculiar, de acordo com suas experiências de vida e de conhecimento. Sujeitos que as elaboram e resignificam a partir de suas experiências vicárias, e as trocam ou socializam entre si, na direção de uma maior e melhor compreensão do mundo, de si mesmos e de seus processos de cognição, pelos quais se humanizam. Entendo que a ampliação do enfoque das mídias no ensino, para além da presença das mídias eletrônicas na escola, precisa abarcar mídias de diferentes naturezas, tais como: o ser humano (professores e alunos principalmente, mas não exclusivamente, no caso da educação escolar), o currículo e os respectivos programas de ensino que o compõem, enquanto mídia que precisa ser apropriada pela mídia humana professor, a fim de ser por ele considerados em função das mídias humanas alunos reais e concretos que tem pela frente, inseridos em uma sociedade que é o referencial necessário para uma atuação docente desencadeadora de um processo de ensino/ aprendizagem significativo e contextualizado para alunos e professores.

6. Na Faculdade de Educação da USP, a senhora já orientou (e orienta) vários trabalhos de mestrado e doutorado na área da Educação e Comunicação. Além disso, neste momento, qual tem sido a sua produção acadêmica nessa área?

Desde 2000 venho me dedicando a estudos e pesquisa sobre o método psicodramático de Jacob Levy Moreno, que engloba uma abordagem interdisciplinar, sociológica, psicológica, artística e comunicacional do comportamento humano, nas dimensões de intra e intercomunicação e de possível comunicação a distância, via TV. Coordenei uma pesquisa até 2005 , cujo objetivo foi a produção de um piloto de telepsicodrama (um projeto de Moreno não realizado em sua época e cuja proposta estamos ajustando aos recursos tecnológicos e conhecimentos da atualidade). Com isso, tenho produzido artigos para a Revista Brasileira de Psicodrama e escrevi um livro que foi publicado em 2007, intitulado Psicodrama, Televisão e Formação de Professores.

Também estou produzindo, no campo de metodologias, textos sobre uma modalidade peculiar de pesquisa-ação, que intitulo pesquisa-ensino, na qual destaco os papéis específicos e intercomplementares do pesquisador acadêmico e do professor do Ensino Básico na produção de conhecimentos sobre ensino.

\section{Os meios de comunicação educam? Como, por que e em que dimensão isso ocorre?}

Sim, os meios de comunicação educam. Todavia é preciso que estejamos alertas quanto ao significado da palavra "educa", que é frequentemente entendida com um sentido positivo, nobre, construtivo. 
Entretanto, educa-se para o bem ou para o mal, para a autonomia ou para a subserviência, para a criação ou para a reprodução. Há saldos positivos das mensagens midiáticas; porém, enquanto comprometidas com o consumismo e com o entretenimento rasteiro, descompromissada com a cultura de qualidade, seu efeito reprodutor, conservador, é muito intenso, quando poderia se pôr a serviço da transformação para uma sociedade mais justa e humana. Mas é preciso não jogar fora a criança com a água do banho. O poder da imagem e da estética televisual nela encerrada (no caso da TV) trabalham a despeito dos interesses comerciais em que a TV se detêm. É por aí que os receptores, que não são uma massa amorfa e nem desprovidos de experiência vicária, podem potencializar efeitos construtivos das mídias. Todavia, para tanto é preciso que se promova uma alfabetização imagética, que desinstaure a concepção de que "a imagem" é simples "reprodução do real" e permita a compreensão de que ela é uma dada versão do real.

8. De forma geral, como a senhora vê a prática pedagógica com os meios de comunicação na escola do século XXI?

Em muitas delas, como recurso publicitário para atrair fregueses, como é o caso de muitas escolas particulares, que dispõem dos meios de comunicação e não dominam a Pedagogia da Comunicação. Em outras, são utilizados apenas como recursos de lazer, sem encaminhamentos didáticos que resultem em processos de ensino/aprendizagem frutíferos. Mas já despontam trabalhos, ainda que pontuais, com mídias no ensino, como atesta a crescente demanda de pós-graduação feita por professores em exercício, dos diferentes níveis de ensino, e muitos trabalhos de professores de ensino fundamental e médio de que temos notícias. Lamentavelmente, penso que ainda é no ensino superior, e especialmente nos cursos de formação de professores, que esse trabalho pedagógico ainda se encontra muito acanhado.

9. É razoável dizer que o consumo das tecnologias informáticas, da internet, irá substituir o consumo de TV no Brasil e que isso justifica que a TV não seja trabalhada na escola? Como a senhora vê esse privilégio por outras tecnologias como o computador na escola?

Como já explicitou Santaella, e como se tem constatado empiricamente, uma mídia não desinstaura outra, mas a ressignifica. TV, vídeo, internet não desbancam a tradicional mídia livro, que ainda hoje, em muitas escolas, lamentavelmente não é trabalhada como mídia, mas como se seus conteúdos fossem verdades petrificadas e eternas, sem autor (quantos alunos sabem o nome dos autores dos livros em que estudam?), sem historicidade! inclusive a Internet traz consigo a necessidade de uma leitura fluente e propicía o exercício da escrita de maneira estimulante. E o poder pedagógico da imagem na TV é diferencial muito importante quando se trata de educação escolar, como consideramos na questão anterior.

10. Fazendo menção ao título do seu livro A televisão na escola: conflito ou cooperação (CORTEZ, 1991), que se tornou uma referência nos estudos que envolvem a relação educação e comunicação, quando há um e quando há outro?

Há conflito quando o professor nega a existência da presença desse meio de comunicação na vida do aluno e na da sociedade como um todo. Cooperação, quando é capaz de uma avaliação serena e competente dele, aprendendo a partir dele o que precisa ter um texto para ser significativo para o aluno e criando formas de trabalho com o texto televisual na escola de tal maneira que não se encerre nele, mas que a partir dele se remeta a textos de naturezas diversas, e propicie relações do aluno com 
a realidade a que se referem, a fim de que possam construir suas próprias versões e desenvolver o raciocínio crítico. Espero que o livro possa esclarecer melhor essa questão.

11. E nos espaços da educação não formal, o que um bom trabalho pedagógico com os meios de comunicação pode trazer de benefícios para os assistidos por essa modalidade educativa?

Considero a própria TV, a internet, como espaços de educação não formal. Quando assumidas por encontros educativos que não na escola, penso que possam ter os mesmos resultados anteriormente considerados, desde que não sejam orientados por propósitos maniqueístas e manipuladores.

12. É bastante recorrente em pesquisas realizadas na academia que os professores, principalmente os que atuam em escolas públicas, sejam tachados de resistentes em relação à inserção dos meios de comunicação na escola. Como a senhora entende essa situação?

Acho perfeitamente compreensível, diante do descuido com a alfabetização para as mídias na formação de professor. Ao contrário do que o senso comum supõe, é preciso aprender a ler textos imagéticos e ainda aprender a pesquisar na internet, com critérios, para além de buscas aleatórias. Pesquisar é diferente de simplesmente buscar. Exige orientação para se saber o que fazer com os dados encontrados que não seja construir uma simples colagem. E para tanto é preciso que os professores saibam pesquisar, e os métodos para isso também se encontram praticamente ausentes hoje em dia em suas formações.

13. Hoje é muito comum, em suas estratégias de propaganda e marketing, instituições de ensino superior falarem em modernos equipamentos tecnológicos em suas práticas educativas. Será que podemos afirmar que essa modernização também afeta os currículos dos cursos, como o de Pedagogia e das licenciaturas, por exemplo? Os professores formados por esses cursos estão realmente preparados para um trabalho significativo com os modernos meios de comunicação em sala de aula? Caso contrário, o que falta para isso?

Creio já ter deixado claro que os professores presentemente não se encontram preparados para esse trabalho. Para tanto seria necessário que os cursos de formação propiciassem, desde o início, a inserção dos professorandos como pesquisadores de situações reais de ensino, a fim de verificarem como mídias são ou não utilizadas no ensino, quais e como. Que estudassem pesquisas que têm por foco o ensino. Que levantassem hipóteses sobre o papel das mídias no ensino, que organizassem pequenos projetos de ensino com mídias e que tivessem oportunidades de realizálos para verificar resultados. Que esses procedimentos de ensino com os professorandos fossem desenvolvidos em faculdades de Educação, nos cursos de licenciatura, devido às especificidades da didática dos diferentes campos do conhecimento, o que exige do formador o domínio desses conhecimentos específicos. Não se trata apenas de aprender procedimentos comunicacionais, mas procedimentos comunicacionais do ensino de História, Geografia, Sociologia, Matemática, Química etc. Entendo que aqui ações formativas interdisciplinares e conjuntas com faculdades de Comunicação seriam muito enriquecedoras, à medida que poderiam introduzir os professorandos e mesmo os formadores em linguagens múltiplas, como as do rádio, da TV, do cinema etc., para uso no ensino dessas diferentes disciplinas. E no curso de Pedagogia o aprendizado dessas linguagens prepararia os pedagogos para o suporte aos projetos de ensino dos professores com as mídias. 
14. Para encerrarmos essa nossa conversa, que característica a senhora julga indispensável aos educadores que queiram fazer um uso adequado dos meios de comunicação na escola?

Considero indispensável que sejam professores reflexivos, indagadores e problematizadores do ensino que realizam. Para tanto é preciso que recuperem suas experiências como alunos na escola de Ensino Básico e que identifiquem nela pontos positivos e pontos problemáticos; que saibam ouvir e levar a sério os seus alunos; que saibam fazer pesquisa-ensino; que saibam levantar hipóteses orientadoras de novos procedimentos de ensino; que saibam trocar ideias, conhecimentos e dificuldades de ensino com seus pares; que gostem de estudar sempre, pois estudo é trabalho de professor. Mas que, sobretudo, amem o ser humano e acreditem e apostem nele, na Educação e em si mesmos. Que acreditem na força e importância de nosso trabalho, a despeito da desconsideração com que é tratado. Pois só assim conseguirão, conseguiremos todos, garra para atuações e reivindicações profissionais conjuntas articuladas em forças de transformação.

\section{REFERÊNCIAS}

PENTEADO, H. D. Televisão e escola: conflito ou cooperação? São Paulo: Cortez, 1991. (Org.). Pedagogia da comunicação: teorias e práticas. São Paulo: Cortez, 1998.

Comunicação escolar: uma metodologia de ensino. São Paulo: Salesiana, 2002.

Psicodrama, televisão e formação de professores. Araraquara: Junqueira e Marin, 2007.

Pesquisa-ensino: comunicação, significação e mídias. São Paulo, 2008. No prelo.

PONTES, A.; PONTES, A. N. (Org.). Pesquisa e prática docente sobre educação e comunicação. Belém, PA: Eduepa, 2008. 